JOURNAL OF THE AMERICAN CHEMICAL SOCIETY 137(12): 4038-4041 (2015)

DOI: $10.1021 / \mathrm{ja} 512658 \mathrm{~m}$ 
This document is confidential and is proprietary to the American Chemical Society and its authors. Do not copy or disclose without written permission. If you have received this item in error, notify the sender and delete all copies.

\section{Chiral Molecular Tweezers: Synthesis and Reactivity in Asymmetric Hydrogenation}

\begin{tabular}{|r|l|}
\hline Journal: & Journal of the American Chemical Society \\
\hline Manuscript ID: & ja-2014-12658m \\
\hline Manuscript Type: & Communication \\
\hline Complete List of Authors: & $\begin{array}{l}\text { Lindqvist, Markus; University of Helsinki, Department of Chemistry } \\
\text { Borre, Katja; University of Helsinki, Department of Chemistry } \\
\text { Axenov, Kirill; University of Helsinki, Department of Chemistry } \\
\text { Kótai, Bianka; Research Centre for Natural Sciences, Theoretical Chemistry } \\
\text { Nieger, Martin; University of Helsinki, Department of Chemistry } \\
\text { Leskela, Markku; University of Helsinki, Department of Chemistry } \\
\text { Pápai, Imre; Research Centre for Natural Sciences, Theoretical Chemistry } \\
\text { Repo, Timo; University of Helsinki, Department of Chemistry }\end{array}$ \\
\hline \hline
\end{tabular}


One of the most efficient and atom-economic ways of preparing chiral amines is through transition metal catalyzed asymmetric hydrogenation of prochiral imines and enamines. ${ }^{1}$ The products, having chiral $\alpha$-carbons, are important in synthetic chemistry due to their application as ligands, resolving agents, chiral auxiliaries and building blocks. Additionally, the chiral information and tendency to form hydrogen bonds, are essential features in molecular recognition, thus making them potential pharmaceuticals. ${ }^{2}$ Drug substance preparation through transition metal catalysis requires tedious product purification due to strict demands on heavy metal residuals in the products. ${ }^{3}$

Recently, main-group systems combining sterically hindered Lewis acids and bases have been reported to cleave molecular hydrogen heterolytically under mild reaction conditions. ${ }^{4}$ The field commonly referred to as the chemistry of "Frustrated Lewis pairs" (FLP) has attracted an increased scientific and practical interest, mainly owing to their applicability as catalysts in homogeneous metal-free hydrogenations of imines, enamines, ${ }^{5} \mathrm{~N}$-heterocycles, ${ }^{6}$ and first results have been disclosed for the hydrogenation of carbonyl compounds ${ }^{7}$ as well. In this regard it is surprising that reports of the corresponding asymmetric reactions are still few. Intermolecular FLP systems involving chiral boranes have been successfully utilized for enantioselective imine hydrogenation. Use of inherently chiral terpene groups (like $\alpha$-pinene and camphor) on boron has proven to be effective for hydrogenation of acetophenone $\mathrm{N}$-arylimines and ee's up to $83 \%$ were reported (Figure $1, \mathbf{1}) .{ }^{8} \mathrm{~A}$ recent development was achieved by introducing chirality through a binaphthyl backbone (2), enabling hydrogenation at room temperature and consequently increasing asymmetric induction. ${ }^{9}$

In intramolecular FLP systems appropriate linking of the Lewis acid and base has proven to be crucial for dihydrogen activation as well as for the hydrogen transfer process. ${ }^{10}$ In ansa-aminoboranes, the Lewis acid and base are in close vicinity, but bulky substituents

hinder dative bond formation. Such structures generate high FLP reactivity and the substrate scope could be expanded to enamines, $\mathrm{N}$-alkyl and alkyl imines. ${ }^{5 \mathrm{~d}, 11}$ However, previous attempts to incorporate high reactivity of ansa-aminoboranes and asymmetric hydrogenation, namely the introduction of chiral amines via straightforward synthetic approaches into linked systems (Figure 1, 3), have resulted in only moderate enantioselectivities. ${ }^{11}$ Herein we report the synthesis of a chiral binaphthyl-linked aminoborane and demonstrate its unique reactivity in enantioselective asymmetric hydrogenation of unhindered imines and enamines. The mechanism of these reactions is also addressed in a computational study.

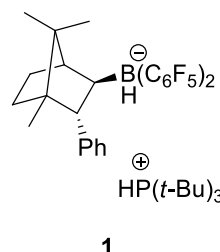

up to $83 \%$ ee $8 \mathrm{~b}$

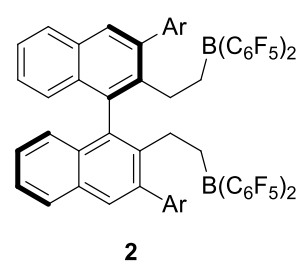

up to $89 \% \mathrm{ee}^{9}$

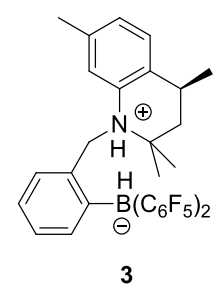

up to $35 \% \mathrm{ee}^{11}$
Figure 1. Previous examples of FLP catalysts for asymmetric hydrogenation of imines.

In our catalyst design, the main objective was to introduce the Lewis acid and base groups into the 2,2'-positions of the rigid asymmetric binaphthyl core fixing their positions next to the asymmetric axis (Scheme 1, $(S)$-8). This arrangement also ensures the close proximity of the amine and boron centers. Another clear benefit of the design is the stability of arene C-B bond, which impedes retrohydroboration and decomposition to olefins and aminoboranes, unlike the alkyl-linked analogues. ${ }^{12}$ This is an evident advantage yet few reported examples of chiral biaryls with $-\mathrm{B}\left(\mathrm{C}_{6} \mathrm{~F}_{5}\right)_{2}$ groups in 2-position exist. ${ }^{13}$

Following the reported synthesis procedure of $(R)-2^{\prime}$-iodo- $N$-isopropyl- $N$-methyl-[1,1'-binaphthalen]-2-amine $[(R)-7]^{14}$ yielded the product in $82 \%$ ee (Scheme 1, route b \& c), as compound 4 has a tendency of racemization during palladium catalyzed reactions. ${ }^{15}$ Therefore a synthetic route via intermediate $(R)-\mathbf{5}$, that could be isolated in good yield and enantiopurity, was designed. ${ }^{16}$ The acetyl group of $(R)-5$ was removed with concentrated hydrochloric acid followed by consecutive primary amine alkylation with isopropyl iodide and methyl iodide. With this approach, the desired product $(R)-7$ was obtained in high enantiopurity, $99 \%$ ee according to 
HPLC. Finally, the aminoborane $(S)-8$, synthesized through straightforward lithiation and reaction with $\mathrm{B}\left(\mathrm{C}_{6} \mathrm{~F}_{5}\right)_{2} \mathrm{Cl}$, was isolated as its ammonium-borohydride salt $(S)-9$ after heterolytic splitting of hydrogen. ${ }^{17}$

Scheme 1. Synthetic routes to enantiopure catalyst (S)-9.

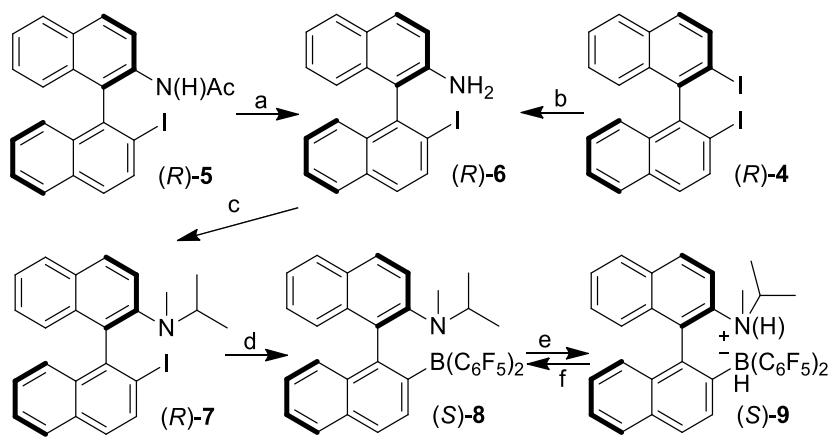

a Reagents and conditions: (a) $\mathrm{EtOH}, \mathrm{HCl}$ conc. $2 \mathrm{~h}$, reflux; (b) $\mathrm{Ph}_{2} \mathrm{C}=\mathrm{NH}, \mathrm{NaO} t$-Bu, cat. $\mathrm{Pd}_{2}(\mathrm{dba})_{3}+$ dppe, toluene, $16 \mathrm{~h}, 100{ }^{\circ} \mathrm{C}$; (c) ${ }^{1)} 2$ eq. $i$-PrI, 2 eq. $\mathrm{K}_{2} \mathrm{CO}_{3}, \mathrm{ACN}, 48 \mathrm{~h}, 120{ }^{\circ} \mathrm{C}$; ${ }^{2)} 2$ eq. MeI, 2 eq. $\mathrm{K}_{2} \mathrm{CO}_{3}$, ACN, $16 \mathrm{~h}, 60{ }^{\circ} \mathrm{C}$; (d) ${ }^{1)}-78{ }^{\circ} \mathrm{C}-\mathrm{RT}$, PhMe, 1 eq. $n-$ BuLi, $3 \mathrm{~h} ;{ }^{2)}-78{ }^{\circ} \mathrm{C}-\mathrm{RT}, 1$ eq. $\mathrm{B}\left(\mathrm{C}_{6} \mathrm{~F}_{5}\right)_{2} \mathrm{Cl}, \mathrm{PhMe}, 16 \mathrm{~h}$; (e) 2 bar $\mathrm{H}_{2}, \mathrm{PhMe}, 1$ min, $\mathrm{RT}$; (f) $\mathrm{C}_{6} \mathrm{D}_{6}, 15 \min , 80{ }^{\circ} \mathrm{C}$.

NMR spectroscopic data of ( $S$ )-9 revealed a single species with ${ }^{11} \mathrm{~B}$ NMR signal at $-19.3 \mathrm{ppm}$ (doublet, ${ }^{1} J_{\mathrm{BH}}=80.8 \mathrm{~Hz}$ ), typical for four coordinate borates. Two different sets of peaks were detected in the ${ }^{19} \mathrm{~F}$ NMR spectrum arising from the diastereotopic pentafluorophenyl groups, both having typical borate pattern and thus confirming the assigned structure $\left(\Delta \delta_{\mathrm{p}, \mathrm{m}}=2.98 ; \Delta \delta_{\mathrm{p}^{\prime}, \mathrm{m}^{\prime}}=3.43\right.$ ppm). In ${ }^{1} \mathrm{H}$ NMR, the B- $H$ was observed as a broad quartet in the region 3.50-2.75 ppm and the ammonium group as a broad singlet at $8.68 \mathrm{ppm}$ also giving rise to doublet splitting on the NMe group $\left(\delta_{\mathrm{H}}=1.18 \mathrm{ppm},{ }^{1} J_{\mathrm{HH}}=6.8 \mathrm{~Hz}\right)$. As a result of diastereotopism, the isopropyl group was detected as two methyl doublets, separated by $0.49 \mathrm{ppm}$.

The X-ray crystallographic study of $(S)-9$ shows a twisted binaphthyl core with a $74.3^{\circ}$ dihedral angle (Figure 2). This sets the Lewis acid and base close to each other in space, even though they are separated by five bonds. The boron center is sterically well protected by the diastereotopic pentafluorophenyl groups oriented edge-to-face and adapting pseudoaxial and pseudoequatorial configurations, an arrangement thought to induce high enantioselectivity in chiral biphenyl diphosphine ligand systems. ${ }^{18}$ The direction of the $-\mathrm{N}(i-\mathrm{Pr})$ moiety is in a $80.9^{\circ}$ angle from the naphthyl plane results in $\mathrm{N}-\mathrm{H} \cdots \cdot \mathrm{H}-\mathrm{B}$ torsional angle of $142^{\circ}$, yet maintaining a short $1.86 \AA \mathrm{H} \cdot \bullet \cdot \mathrm{H}$ distance. ${ }^{19}$

Formation of the colorless ammonium-borohydride (S)-9, upon exposing the deep red aminoborane $(S)-\mathbf{8}$ to hydrogen, is rapid and quantitative conversion occurs in less than 1 min placing it as one of the fastest reactions we have studied in FLP hydrogen activation (Scheme 1, e). Quantitative dehydrogenation of (S)-9 occurred within $15 \mathrm{~min}$ at $80{ }^{\circ} \mathrm{C}$ (Scheme $\left.1, \mathrm{f}\right)$. The catalytic activity of $(S)$ 9 was studied and the reaction conditions were optimized in a series of hydrogenation experiments with substrate $\mathbf{1 0}$ (Table 1). Starting with $10 \mathrm{~mol} \%$ catalyst loading in toluene, the reaction at room temperature under 2 bar hydrogen pressure gave $28 \%$ conversion in 16 $\mathrm{h}$ (entry 1). Prolonging the reaction time by a factor of four and simultaneously reducing catalyst concentration to half nearly doubled the conversion confirming the catalyst's stability (entry 2). Quantitative hydrogenations were observed at elevated temperatures, but only with moderate ee (entry 3 ). Aiming for higher reaction rate and enantioselectivity we varied the solvent. As already shown earlier, ${ }^{11}$ a remarkable increase in activity and enantioselectivity was detected in ethereal solvents (cf. entry 1, and 4). The reaction rate in methyl tert-butyl ether (MTBE) was superior in comparison to diethyl ether while the enantioselectivity remained unchanged (cf. entry 5 and 6). Finally, a conversion of $94 \%$ and $83 \%$ ee could be obtained with substrate $\mathbf{1 0}$ using $7.5 \mathrm{~mol} \%$ catalyst loading (Table 2, entry 8 ).

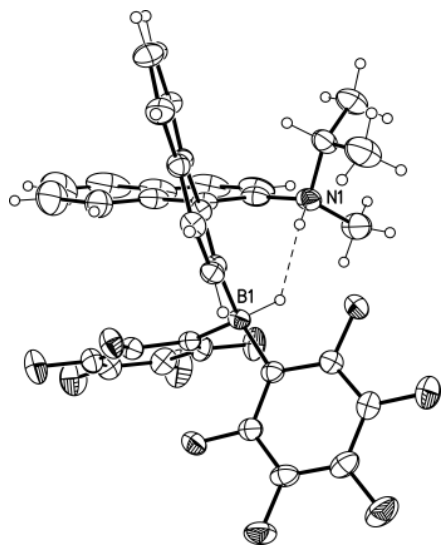

Figure 2. Crystal structure of $(S)-\mathbf{9}$ with $50 \%$ probability ellipsoids (solvent molecule omitted for clarity).

Table 1. Catalytic hydrogenation of imine 10 by ammonium-borohydride $(S)-9$ in different reaction conditions.

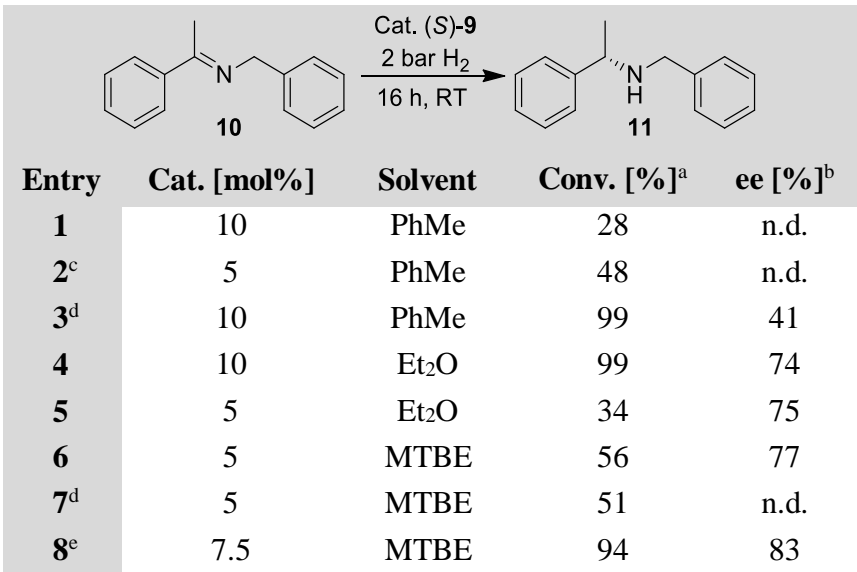

Reaction conditions: (S)-9 (0.01-0.02 mmol), $1042 \mathrm{mg}(0.2$ mmol), $1 \mathrm{ml}$ solvent. ${ }^{\mathrm{a}}$ by ${ }^{1} \mathrm{H}$ NMR spectroscopy. ${ }^{\mathrm{b}}$ by HPLC, (Chiralcel OD-H column) ${ }^{\mathrm{c}}$ Reaction time 64 h. ${ }^{\mathrm{d}} 10$ bar $\mathrm{H}_{2}$ pressure. ${ }^{\mathrm{e}}$ Reaction time $20 \mathrm{~h}$.

To continue our experimental investigation we studied the reactivity of $(S)-9$ with a range of different substrates. Various $N$-alkyl and $N$-benzyl alkyl aryl ketimines were hydrogenated in $75-83 \%$ ee, independently on size of the $N$-substituent (Table 2, 11-13). The FLP activity was remarkably high with small $N$-methyl imines, despite of producing small amines that commonly reduce the activity by forming deactivating B-N adducts ( $12 \&$ 15). Bulkier $N$-benzyl imine substrates, requiring increased catalyst loading and longer reaction times, also gave products with high yield and enantiopurity $(11,13 \& 14)$. The sterically most encumbered and the least basic imine in our series ( $N$-( $p$-methoxyphenyl) acetophenone imine) was not reduced quantitatively even under elevated temperatures and product $\mathbf{1 6}$ was obtained in $53 \%$ conversion. These results describe interesting, reverse substrate preference of $(S)$-9 in comparison to previous FLP catalysts and are a fingerprint of an exceptionally hindered borane (see Figure 2). ${ }^{11}$ 
Table 2. Catalytic asymmetric hydrogenations of imines and enamines catalyzed by the ammonium-borohydride (S)-9.

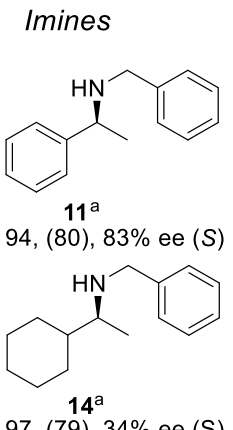

$97,(79), 34 \%$ ee $(\mathrm{S})$

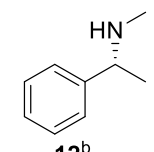

$12^{\mathrm{b}}$

$99,(92), 75 \%$ ee $(R)$

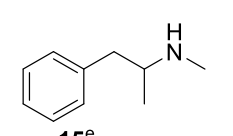

$97,(72), 32 \% \mathrm{ee}^{\mathrm{f}}$ (n.d.)

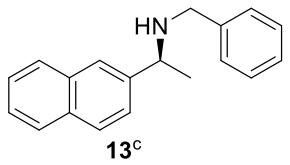

$93,(79) 76 \%$ ee $(S)$

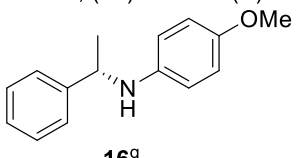

$53,(34), 36 \%$ ee $(S)$
Enamines

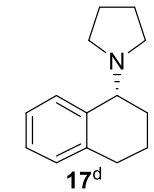

99, $(95), 99 \%$ ee $(R)^{19}$

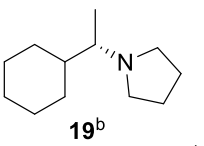

$99,(42), 85 \% \mathrm{ee}^{\mathrm{h}}(S)$

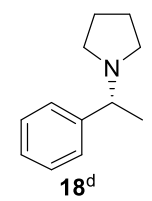

$99,(81), 95 \%$ ee $(R)$

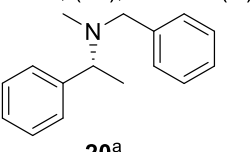

$99,(85), 47 \%$ ee $(R)$

${ }^{1} \mathrm{H}$ NMR conversion [\%], (Isolated yield [\%]), ee by HPLC (Chiralcel, OD-H or OD-J column). Reaction conditions: 2 bar $\mathrm{H}_{2}$, substrate (200 $\mu \mathrm{mol}), 1 \mathrm{ml} \mathrm{MTBE}, 25^{\circ} \mathrm{C}^{.}{ }^{\mathrm{a}}(S)-9(15 \mu \mathrm{mol}), 20 \mathrm{~h}^{\mathrm{b}}(S)-\mathbf{9}(5 \mu \mathrm{mol}), 16 \mathrm{~h}^{\mathrm{c}}{ }^{(}(S)-9(10 \mu \mathrm{mol}), 20 \mathrm{~h}^{\mathrm{d}}{ }^{(S)-9}(5 \mu \mathrm{mol}), 0.5 \mathrm{~h} .{ }^{\mathrm{e}}(S)-9(10 \mu \mathrm{mol})$, $16 \mathrm{~h}$. ${ }^{\mathrm{f}}$ ee by ${ }^{1} \mathrm{H}$ NMR as diasteromers with $O$-acetylmandelic acid. ${ }^{\mathrm{g}}(S)-9(20 \mu \mathrm{mol}), 60{ }^{\circ} \mathrm{C}, 64 \mathrm{~h}$ (PhMe used as solvent). ${ }^{\text {h }}$ ee by optical rotation.

Although (S)-9 prefers small imines for hydrogenation, stereoselective hydrogenation of alkyl imines remain challenging due to the chemically similar groups on both sides of the $\mathrm{C}=\mathrm{N}$ carbon. The catalyst $(S)$-9 yielded alkyl amines $\mathbf{1 4}$ and $\mathbf{1 5}$ in over $30 \%$ ee, which are noteworthy values compared to previous FLP results. ${ }^{9,11}$

Remarkably, $\mathrm{N}, \mathrm{N}$-symmetric enamines were quantitatively converted to corresponding amines with extremely high optical purity (Table $2,17 \&$ 18). Alkyl amine 19 was also obtained in high optical purity, $85 \%$ ee. Unequal $\mathrm{N}$-alkyl groups decreased the enantioselectivity, which is attributed to the formation of an iminium intermediate and possibility of $E / Z$-isomerism (Table 2, 20). The results with $N, N$-alkyl enamines are particularly important as they belong to the most challenging substrates for transition metal catalysts. $^{1 b}$

To gain insight into the mechanism of present hydrogenation reactions and into the origin of the observed stereoselectivity, we explored possible reaction pathways for the formation of amine $\mathbf{1 7}$ in a computational study. We used DFT calculations to identify and characterize relevant transition states and corresponding reaction intermediates. ${ }^{20}$ The results are summarized in terms of a free energy diagram as depicted in Figure 3.

In line with our experimental observations, calculations predict fairly low barrier $(14.7 \mathrm{kcal} / \mathrm{mol})$ for the heterolytic $\mathrm{H}_{2}$ splitting induced by aminoborane $(S)-\mathbf{8}$ (referred to as cat in Figure 3 ). This reaction is found to be clearly exergonic at standard conditions, however, the reverse process $\left(\mathrm{H}_{2}\right.$ elimination) becomes feasible at higher temperatures and using nonpolar solvents. ${ }^{21}$

The computational results support the view that hydrogen transfer from the hydrogenated FLP to enamines occurs in two distinct steps and it is initiated by protonation of the substrate, which is then followed by a hydride transfer process. ${ }^{22}$ The barrier of this latter step is found to be slightly higher than that of the protonation $(23.5$ and $21.8 \mathrm{kcal} / \mathrm{mol}$, respectively) suggesting that the hydride transfer is likely to be rate-determining in the catalytic cycle. The most stable form of the hydridoborate/iminium ion pair intermediate formed upon the protonation is computed to be at $-9.9 \mathrm{kcal} / \mathrm{mol}$ in free energy (see int in Figure 3), however, several other low-lying and easily interchangeable forms could be identified for this species. These isomeric forms differ in the orientation of the aryl substituents at the boron center and also in the relative position of the interacting iminium ion. The $\mathrm{BH}^{-}$unit of the hydrido borate species is embedded in a chiral environment, which enables stereoselective attack of the iminium ion. Hydride transfer to the $R e$ face of the iminium is predicted to be kinetically favored (by $1.4 \mathrm{kcal} / \mathrm{mol}$ ) as compared to the attack of the $\mathrm{Si}$ face, which is consistent with the observed enantioselectivity (excess of $R$ product). Our analysis on the origin of stereoselectivity reveals that the energy difference obtained for the competing transition states is a result of subtle balance between repulsive steric and attractive noncovalent interactions in the stereoselectivity determining hydride transfer step (see Figure 4 and also SI ).

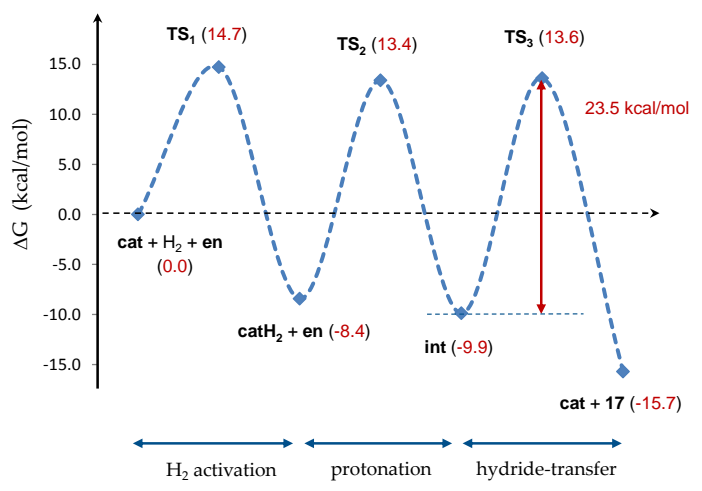

Figure 3. Gibbs free energy diagram computed for the formation of amine 17.

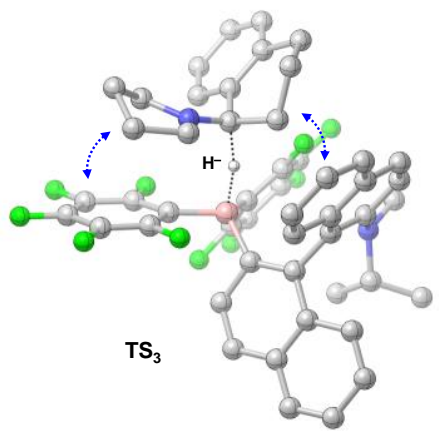

Figure 4. Transition state of the hydride transfer yielding the major product enantiomer. Intermolecular contacts are highlighted by blue arrows. $\mathrm{CH}$ hydrogen atoms are omitted for clarity.

In summary, chiral bridged binaphthyl aminoborane catalyst for highly enantioselective hydrogenation is reported. A wide variety of structurally different substrates react readily at mild conditions with enantioselectivity up to $99 \%$ ee. Unhindered $N$-alkylimines are readily hydrogenated without catalyst-product adduct formation, in contrast to what is typical for FLPs. Most importantly, 
the first results of FLP catalyzed asymmetric hydrogenations of enamines are presented. Because the catalyst itself can be synthesized from readily available starting materials in high enantiopurity, the simplicity of the synthesis and overall structure makes $(S)$ 9 as a good candidate for further development in asymmetric metalfree hydrogenation.

\section{ASSOCIATED CONTENT}

\section{Supporting Information}

Experimental procedures, characterization data (X-ray crystallography data (cif-file) and copies of HLPC chromatograms) and computational methods. This material is available free of charge via the Internet at http://pubs.acs.org. Structure parameters for compounds $(S)-\mathbf{9},(R)-\mathbf{9}$ and $(R)-\mathbf{1 7} \cdot \mathrm{HCl}$ are available from Cambridge Crystallographic Data Centre under references CCDC-1036946, CCDC1036947 and CCDC-1036948, respectively.

\section{AUTHOR INFORMATION}

\section{Corresponding Author}

papai.imre@ttk.mta.hu, timo.repo@helsinki.fi

\section{Notes}

The authors declare no competing financial interest.

\section{ACKNOWLEDGMENT}

This work was supported by the Academy of Finland (139550, 276586), the Inorganic Materials Chemistry Graduate Program, COST action CM0905, and the Hungarian Scientific Research Fund (OTKA, K-81927).

\section{REFERENCES}

(1) Selected reviews on transition metal catalyzed asymmetric hydrogenation of enamines and imines: (a) Spindler, F.; Blaser, H.-U. Enantioselective Hydrogenation of $\mathrm{C}=\mathrm{N}$ Functions and Enamines. In Handbook of Homogenous Hydrogenation; de Vries, J. G., Elsevier, C. J., Eds.; WileyVCH: Weinheim, 2007; Vol. 3, pp 1193-1214. (b) Xie, J.-H.; Zhu, S.-F.; Zhou, Q.-L. Chem. Rev. 2011, 111, 1713-1760. (c) Yu, Z.; Jin, W.; Jiang, Q. Angew. Chem. Int. Ed. 2012, 51, 6060-6072. (d) Xie, J.-H.; Zhu, S.-F.; Zhou, Q.-L. Chem. Soc. Rev. 2012, 41, 4126-4139

(2) (a) Nugent, T. C. Chiral Amine Synthesis: Methods, Developments and Applications, Wiley-VCH, Weinheim, 2010. (b) Nugent, T. C.; El-Shazly, M. Adv. Synth Catal. 2010, 352, 753-819.

(3) (a) Garrett, C. E.; Prasad, K. Adv. Synth. Catal. 2004, 346, 889990. (b) Dalko, P. I.; Moisan, L. Angew. Chem. Int. Ed. 2001, 40, 37263748.

(4) (a) Welch, G. C.; San Juan, R. R.; Masuda, J. D.; Stephan, D. W. Science 2006, 314, 1124-1126. (b) Stephan, D. W. Org. Biomol. Chem. 2008, 6, 1535-1539. (c) Stephan, D. W.; Erker, G. Angew. Chem. Int. Ed. 2010, 49, 171-177. (d) Powers, P. P. Nature 2010, 463, 171-177 (e) Erker, G. C. R. Chimie 2011, 14, 831-841. (f) Stephan, D. W. Org. Biomol. Chem. 2012, 10, 5740-5746. (g) Hounjet, L. J.; Stephan, D. W. Org. Process Res. Dev. 2014, 18, 385-391. (h) Paradies, J. Angew. Chem. Int. Ed. 2014, 53, $3552-3557$.

(5) (a) Chase. P. A.; Welch, G. C.; Jurca, T.; Stephan, D. W. Angew. Chem. Int. Ed. 2007, 46, 8050-8053. (b) Spies, P.; Schwendemann, S.; Lange, S.; Kehr, G.; Fröhlich, R.; Erker, G. Angew. Chem. Int. Ed. 2008, 47, 7543-7546. (c) Chase, P. A.; Jurca, T. Stephan, D. W. Chem. Commun. 2008, 1701-1703. (d) Sumerin, V.; Schulz, F.; Atsumi, M.; Wang, C.; Nieger, M.; Leskelä, M.; Repo, T.; Pyykkö, P.; Rieger, B. J. Am Chem. Soc. 2008, 130, 14117-14119. (e) Jiang, C.; Blacque, O.; Berke, H. Chem. Commun. 2009, 5518-5520. (f) Rokob, T. A.; Hamza, A.; Stirling, A.; Pápai, I. J. Am. Chem. Soc. 2009, 131, 2029-2036. (g) Axenov, K. V; Kehr, G.; Frölich, R.; Erker, G. J. Am. Chem. Soc. 2009, 131, 3454-3455. (h) Axenov, K. V; Kehr, G.; Frölich, R.; Erker, G. Organometallics 2009, 28, 51485158. (i) Erős, G.; Mehdi, H.; Pápai, I.; Rokob, T. A.; Király, P.; Tárkányi,
G.; Soós, T. Angew. Chem. Int. Ed. 2010, 49, 6559-6563. (j) Farrell, J. M.; Hatnean, J. A.; Stephan, D. W. J. Am. Chem. Soc. 2012, 134, 15728-15731. (k) Chernichenko, K.; Nieger, M.; Leskelä, M.; Repo, T. Dalton Trans. 2012, 41, 9029-9032. (1) Wang, G.; Chen, C.; Du, T.; Zhong, W. Adv. Synth. Catal. 2014, 356, 1747-1752. (m) Hatnean, J. A.; Thomson, J. W.; Chase, P. A.; Stephan, D. W. Chem. Commun. 2014, 50, 301-303.

(6) (a) Geier, S. J.; Chase, P. A.; Stephan, D. W. Chem. Commun. 2010, 46, 4884-4886. (b) Stephan, D. W.; Greenberg, S.; Graham, T. W.; Chase, P.; Hastie, J. J.; Geier, S. J.; Farrell, J. M.; Brown, C. C.; Heiden, Z. M.; Welch, G. C.; Ullrich, M. Inorg. Chem. 2011, 50, 12338-12348. (c) Erős, G.; Nagy, K.; Pápai, I.; Nagy P.; Király, G.; Tárkányi, G.; Soós, T. Chem.-Eur. J. 2012, 18, 574-585. (d) Scott, D. J.; Fuchter, M. J.; Ashley, A. E. Angew. Chem. Int. Ed. 2014, 53, 10218-10222. (e) Clark, E. R.; Ingleson, M. J. Angew. Chem. Int. Ed. 2014, 53, 11306-11309.

(7) (a) Mahdi, T.; Stephan, D. W. J. Am. Chem. Soc. 2014, 136, 15809-15812. (b) Scott, D. J.; Fuchter, M. J.; Ashley, A. E. J. Am. Chem. Soc. 2014, 136, 15813-15816.

(8) (a) Chen, D.; Klankermayer, J. Chem. Commun. 2008, 2130 2131. (b) Chen, D.; Wang, Y.; Klankermayer, J. Angew. Chem. Int. Ed. 2010, 49, 9475-9478. (c) Ghattas, G.; Chen, D.; Pan, F.; Klankermayer, J. Dalton Trans. 2012, 41, 9026-9028.

(9) Liu, Y.; Du, H. J. Am. Chem. Soc. 2013, 135, 6810-6813.

(10) (a) Rokob, T. A.; Hamza, A.; Pápai, I. J. Am. Chem. Soc. 2009, 131,10701-10710. (b) Rokob, T. A.; Pápai, I. Top. Curr. Chem. 2013, 332, $157-212$.

(11) Sumerin, V.; Chernichenko, K.; Nieger, M.; Leskelä, M.; Rieger, B.; Repo. T. Adv. Synth. Catal. 2011, 353, 2093-2110.

(12) (a) Singaram, B.; Goralski, C. T.; Rangaishenvi, M. V.; Brown, H. C. J. Am. Chem. Soc. 1989, 111, 384-386. (b) Sigaram, B.; Rangaishenvi, M. V.; Brown, H. C.; Goralski, C. T.; Hasha, D. L. J. Org. Chem. 1991, 56, 1543-1549. (c) Singaram, B.; Goralski, C. T.; Fisher, G. B. J. Org. Chem. 1991, 56, 5691-5696. (d) Parks, D. J.; Piers, W. E.; Yap, G. P. A. Organometallics 1998, 17, 5492-5503. (e) Schwendemann, S.; Oishi, S.; Saito, S.; Fröhlich, R.; Kehr, G.; Erker, G. Chem.-Asian J. 2012 8, 212-217. (f) Lindqvist, M.; Axenov, K.; Nieger, M.; Räisänen, M.; Leskelä, M.; Repo, T. Chem.-Eur. J. 2013, 19, 10412-10418.

(13) Morrison, D. J.; Piers, W. E.; Parvez, M. Synlett 2004, 24292433.

(14) García-Fortanet, J.; Kessler, F.; Buchwald, S. L. J. Am. Chem. Soc. 2009, 131, 6676-6677.

(15) (a) Juríček, M.; Brath, H.; Kasák, P.; Putala, M. J. Organomet. Chem. 2007, 692, 5279-5284. (b) Brath, H.; Mešková, M.; Putala, M. Eur. J. Org. Chem. 2009, 3315-3318.

(16) Mešková, M.; Putala, M. Tetrahedron Lett. 2011, 52, 53795383.

(17) Aminoborane (S)-8 was analyzed by ${ }^{1} \mathrm{H}$ and ${ }^{19} \mathrm{~F}$ NMR spectroscopy. Due to high moisture and air sensitivity, isolation as pure substance or full characterization of this species has not been successful.

(18) Jeulin, S.; de Paule, S. D.; Ratovelomanana-Vidal, V.; Genet, J.- P.; Champion, N.; Dellis, P. Proc. Natl. Acad. Sci. U.S.A. 2004, 101, 5799-5804.

(19) The absolute configuration of $(S)-\mathbf{9},(R)-\mathbf{9}$ and $(R)-\mathbf{1 7} \cdot \mathbf{H C l}$ were determined crystallographically using the effects of anomalous dispersion (see also SI)

(20) DFT calculations carried out at the $\omega B 97 X-D / 6-311 G(d, p)$ level were used for geometry optimizations, vibrational analysis and the estimation of solvent effects. Additional single-point energy calculations with the $6-311++\mathrm{G}(3 \mathrm{df}, 3 \mathrm{pd})$ basis set were also performed for each structure to increase the accuracy of electronic structure predictions. The energetics reported in the paper corresponds to solution-phase Gibbs free energies (solvent $=$ diethyl ether). Further computational details are provided in the Supplementary Information.

(21) The exergonicity of $\mathrm{H}_{2}$ activation is reduced notably for conditions used in dehydrogenation experiments $(\Delta \mathrm{G}=-5.0 \mathrm{kcal} / \mathrm{mol}$ for $\mathrm{T}=80$ ${ }^{\circ} \mathrm{C}$ and solvent $=$ benzene). Note also that the continuous release of $\mathrm{H}_{2}$ from the solution shifts the reaction towards $\mathrm{H}_{2}$ elimination. These non-equilibrium conditions are not taken into account in the present computational approach.

(22) (a) Schwendemann, S.; Tumay, T. A.; Axenov, K. V.; Peuser, I.; Kehr, G.; Fröhlich, R.; Erker, G. Organometallics 2010, 29, 1067-1069. (b) Stephan, D. W.; Erker, G. Top. Curr. Chem. 2013, 332, 85-110. 


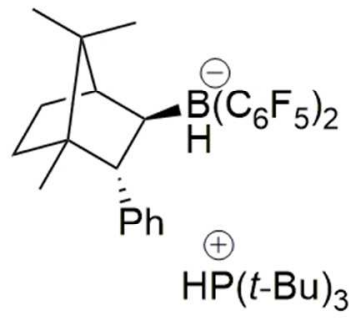

1

up to $83 \% e^{8 b}$

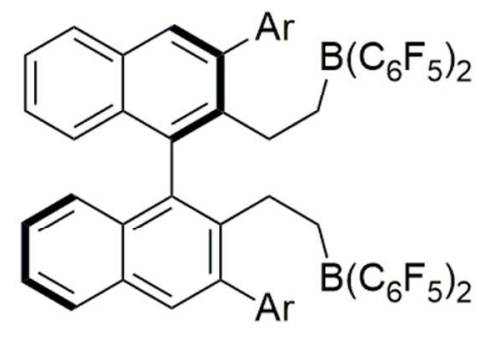

2

up to $89 \% \mathrm{ee}^{9}$

$82 \times 33 \mathrm{~mm}(300 \times 300$ DPI $)$

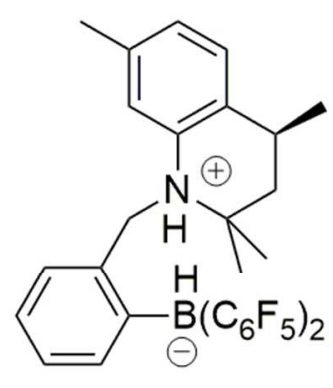

3

up to $35 \%$ ee 11 


1
2
3
4
5
6
7
8
9
10
11
12
13
14
15
16
17
18
19
20
21
22
23
24
25
26
27
28
29
30
31
32
33
34
35
36
37
38
39
40
41
42
43
44
45
46
47
48
49
50
51
52
53
54
55
56
57
58
60<smiles>CC(C)Nc1ccc2ccccc2c1-c1c(Br)ccc2ccccc12</smiles>

$84 \times 44 \mathrm{~mm}(300 \times 300$ DPI $)$ 


\section{Unable to Convert Image \\ The dimensions of this image (in pixels) are too large to be converted. For this image to convert, the total number of pixels (height $x$ width) must be less than 40,000,000 (40 megapixels).}


1

2

3

4

5

6

7

8

9

10

11

12

13

14

15

16

17

18

19

20

21

22

23

24

25

26

27

28

29

30

31

32

33

34

35

36

37

38

39

40

41

42

43

44

45

46

47

48

49

50

51

52

53

54

55

56

57

58

59

60<smiles>[R7][R17]([H])(c1cccc(CN=C(C)c2ccccc2)c1)c1cccc([C@@H](C)NCc2ccccc2)c1</smiles>

$68 \times 14 \mathrm{~mm}(300 \times 300$ DPI $)$ 
Imines

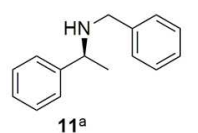

94, (80), $83 \%$ ee (S)

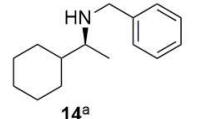

97, $(79), 34 \%$ ee (S)

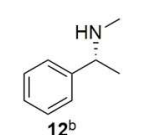

9, (92), $75 \%$ ee $(R)$

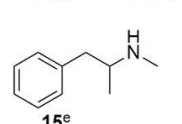

97. 172 ) $32 \%$ eef (n.d.)

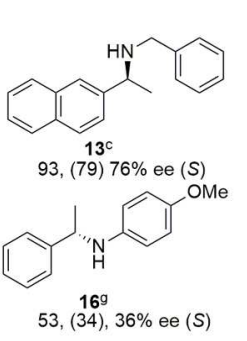

Enamines

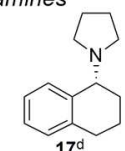

99, $(95), 99 \%$ ee $(R)^{19}$

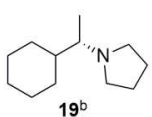

99, (42), 85\% ee $\mathrm{e}^{\mathrm{h}}(\mathrm{S})$

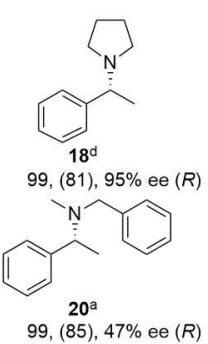

$167 \times 46 \mathrm{~mm}(300 \times 300 \mathrm{DPI})$ 
1

2

3

4

5

6

7

8

9

10

11

12

13

14

15

16

17

18

19

20

21

22

23

24

25

26

27

28

29

30

31

32

33

34

35

36

37

38

39

40

41

42

43

44

45

46

47

48

49

50

51

52

53

54

55

56

57

58

59

60

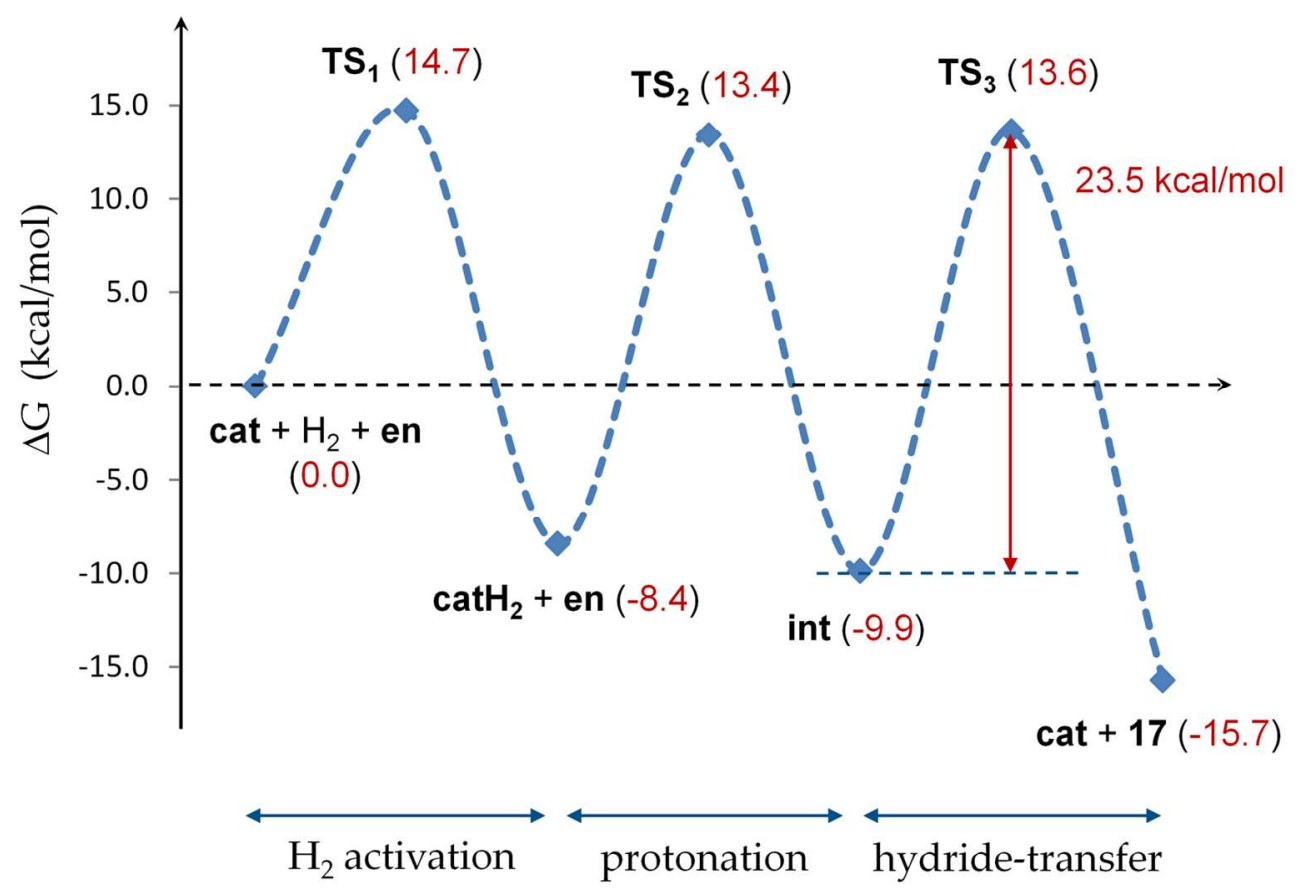

$142 \times 98 \mathrm{~mm}(300 \times 300$ DPI $)$ 


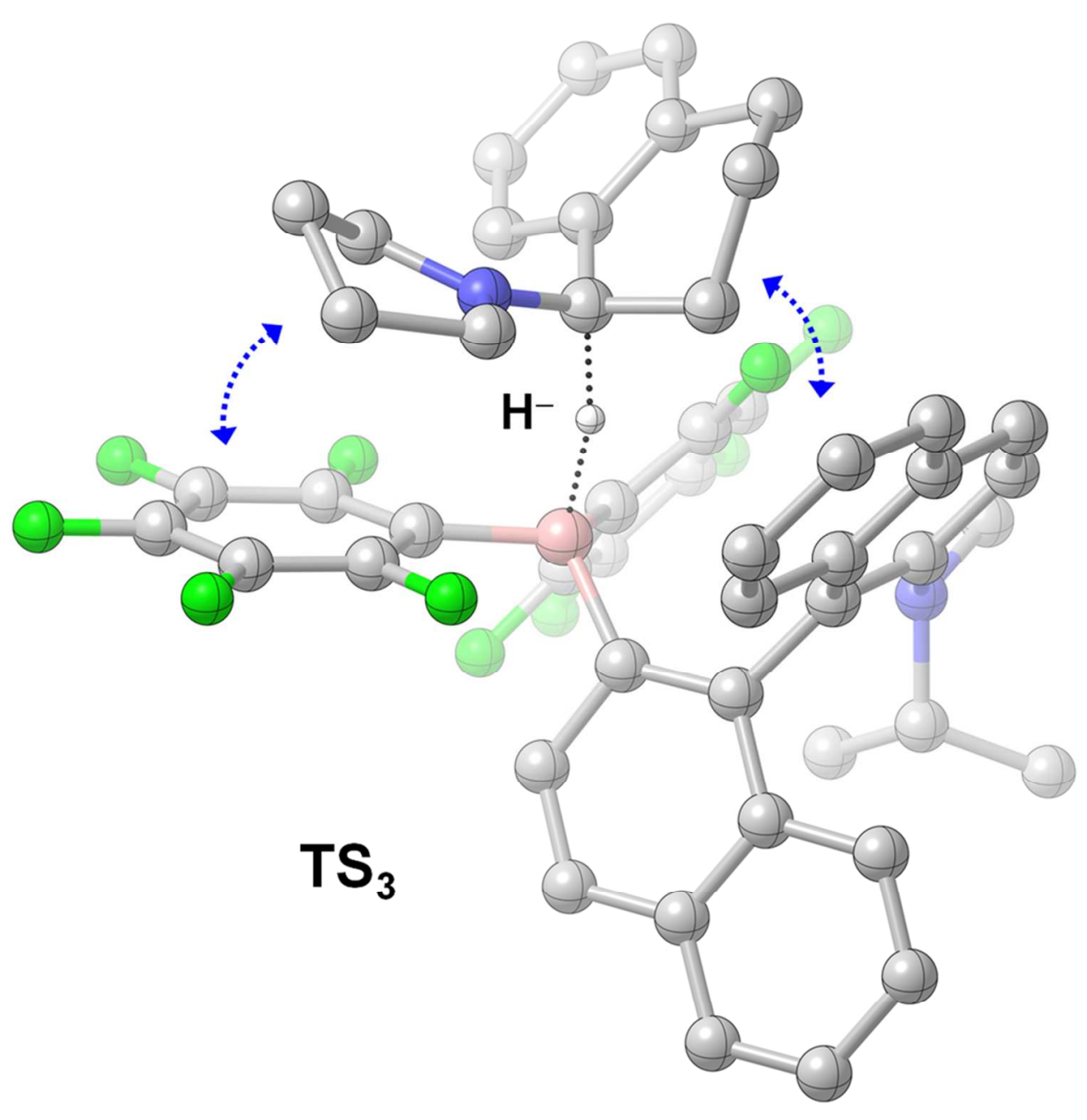

$90 \times 88 \mathrm{~mm}(300 \times 300 \mathrm{DPI})$ 


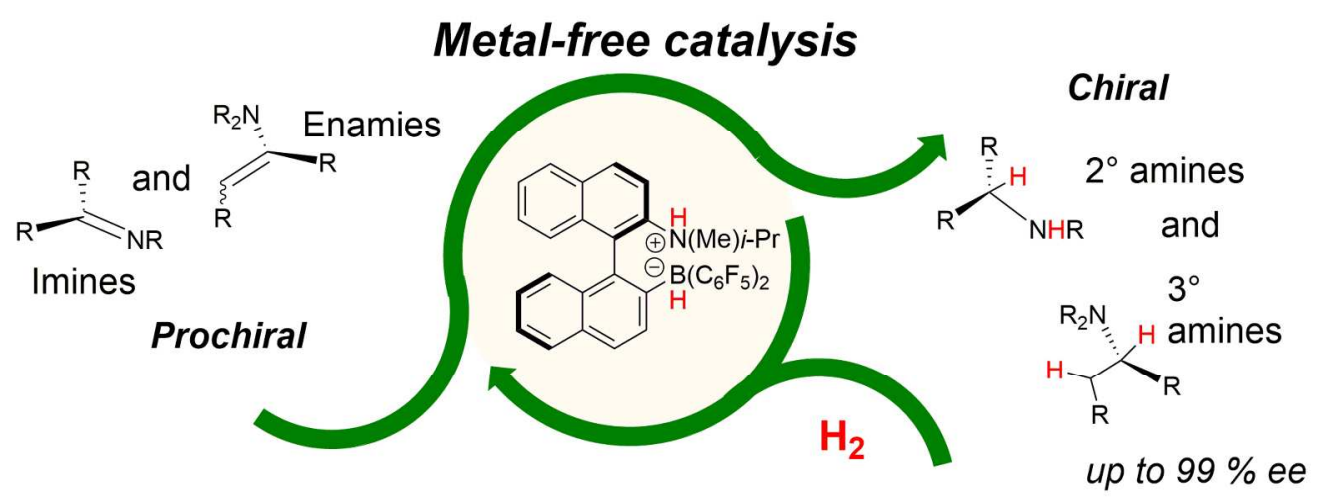

$179 \times 67 \mathrm{~mm}(300 \times 300 \mathrm{DPI})$ 